\title{
The role of a stand-alone ICT course in a Malaysian Public University: How effective is it for student teachers?
}

\begin{abstract}
This research attempts to measure student teachers' confidence toward ICT and their perceived ICT skills after completing a stand-alone ICT course at Universiti Putra Malaysia. Two separate paired samples t-tests results revealed that there was a positive shift in the student teachers' confidence toward ICT as well as an improvement in their perceived ICT skills towards the end of the course. The pre-test result showed that participants with lower prior ICT experience were as confident as those with higher experience before enrolling in the course. They, however, had much lower perceived ICT skills. The post test results showed that those with lower prior ICT experience still had similar confidence level toward ICT compared to those with higher prior computer experience but the gap between their perceived ICT skills had reduced. The responses obtained from interviewing six student teachers showed that participants were more confident with ICT related tools and felt that their ICT skills improved towards the end of the stand-alone course. The study offered some evidence that stand-alone ICT courses can benefit student teachers.
\end{abstract}

Keyword: Stand-alone ICT Course, Student Teachers, Confidence Towards ICT, Perceived ICT Skills 